\title{
Making the Implicit Explicit: the Grammar of Inferential Reasoning in the Humanities and Social Sciences
}

\author{
Kathy Luckett \\ Humanities Education Development Unit and Department of Sociology, University of Cape Town, South Africa
}

Copyright $(2016$ by authors, all rights reserved. Authors agree that this article remains permanently open access under the terms of the Creative Commons Attribution License 4.0 International License

\begin{abstract}
This is a theoretical paper that addresses the challenge of educational access to the Humanities and Social Sciences. It plots a theoretical quest to develop an explicit pedagogy to give 'disadvantaged' students in the Humanities ways of working successfully with texts. In doing so it draws on Bernstein, Moore and Maton's work to theorize the nature of knowledge in the Humanities, and also on Brandom's analysis of inferential reasoning. It uses elements of Systemic Functional Linguistics (SFL) to analyse student texts. The empirical work reported on here is work-in-progress and represents no more than an indication of the approach advocated. The approach is illustrated by examples from comprehension exercises designed to promote students' inferential reasoning. Selected findings are presented to illustrate the extent of the challenge entailed in facilitating access to Humanities texts. The paper concludes by suggesting that mastery of ways of working with texts in the Humanities entails attending to the acquisition of both recognition and realization rules for reading and writing.
\end{abstract}

Keywords Higher Education, Humanities, Education Development, Inferential Reasoning, Systemic Functional Linguistics, Epistemic Access

\section{Background}

This paper reflects on what might be an appropriate approach to education development for students (ED) in the Humanities in South Africa - a country where an impoverished public schooling system means that the participation rate in higher education is only $13 \%$ for black students compared with $60 \%$ for white students [1]. Furthermore, the attrition rate is very high - at the end of the regulation time for undergraduate qualifications more students have been lost to failure and dropout than have graduated. Despite the fact that the field of ED in South Africa has three and a half decades of experience and theoretical development[2], the structural challenges faced by the field remain severe and are as yet inadequately interrupted by ED interventions. The challenge faced is shared by many universities globally, particularly those where first-generation students are admitted[3]. The challenge is how best to use limited curriculum time and resources to enable students to master the ways of thinking, reading and writing in the disciplines. This calls for curriculum and pedagogic strategies of high leverage, which in turn demand a strongly theoretically informed approach. This paper is one attempt to map the latter.

Of course, this challenge is not new. Since the 1980s it has been variously addressed through a range of approaches developed to teach reading and writing or 'academic literacies' to undergraduate students[4-9]. Lea and Street[10] identify three models of teaching student writing in higher education: study skills, academic socialisation and academic literacies. I use their schema to briefly discuss each of these below and suggest a fourth approach that I have termed the 'epistemic access' approach [11, 12].

The 'study skills' approach is described by Ivanic[13] as a 'skills discourse' where the focus is on the explicit teaching of decontextualized rules and patterns of language - where writing is viewed as a unitary, context-free skills set that is transferable across contexts. Early ED interventions from the 1980s in South African universities adopted this approach [14]. Such interventions were typically bridging, non-credit-bearing and 'add-on' and did not engage with disciplinary content or disciplinary specific ways of using language. Boughey[15] critiques this approach for assuming an autonomous, instrumental view of literacy and a deficit model of 'disadvantaged' students. It is now widely accepted that a major limitation of this approach is the separation of skills (knowing how) from specialized content knowledge (knowing that). The argument about the importance of holding together procedural (knowing how) and propositional knowledge (knowing that) is developed below.

In the 'academic socialization' approach the focus shifted to embedding the 'knowing how' in the 'knowing what'. The nature of the disciplinary discourses and their genres were 
identified in an attempt to make their demands explicit to students (see for example Hasan \&Williams[16], Hyland[17] and Swales[18]). The academic socialization approach would include Ivanic's[19] 'genre discourse' of writing pedagogy. This approach has affinities with the work of the Sydney school of SFL (see for example Rose \& Martin[20]).

Despite the importance of the shift away from generic to discipline specific ways of writing, the 'academic socialization' approach was critiqued by Lea and Street[21] for taking as given the discursive demands of powerful institutions and ignoring students' needs and experiences. Drawing on the New Literacy Studies and critical discourse analysis, the 'academic literacies' approach views literacy events as culturally situated social practices within powerful institutions and discourses that have ideological effects that implicate students' social identities and values. The ideological stance of the academic literacies approach claims to be critical and transformative; it looks beyond the text to challenge unequal social relations [22]. The focus of this approach is on the student's lived experience and on what is at stake for writers, with regard to identity and power relations, when confronted with conventional academic texts. Texts are viewed as dynamic, hybrid and open to contestation and change - writers are encouraged to recognize but also resist orthodox positionings. This approach draws on linguistic ethnography to capture writers' emic accounts - using talk around texts, in-depth interviews as well as the texts themselves as data. It is interested in how students articulate their voices in academic writing and how institutionalized conventions constrain the meaning-making potential of non-traditional students.

The academic literacies approach has been widely adopted by ED practitioners teaching black students in South African universities where 'educational disadvantage' gets re-framed as socially and culturally constituted by a colonial society through the imposition of its dominant linguistic, curricula and pedagogic social practices. In the 1980s and 1990s during the anti-apartheid struggle, it is not surprising that this approach struck a chord with ED practitioners particularly in liberal, South African universities. Working from a critical or emancipatory paradigm, in a context of vast social inequality, teachers of academic literacy adopted this approach to challenge the power differentials in contested colonial literacy practices and to validate the semiotic resources brought to the academy by first generation black students. Indeed, given certain conditions, this approach is empowering for learners from oppressed social groups. It can help them find a voice and take a position against dominant and often alienating cultures. Perhaps more importantly, as a pedagogic strategy, it provides safe social spaces where students can practise acquiring 'knowing how' to read and write academic texts - in Bernsteinian terms, acquiring the requisite 'realization rules' [23].

However, Ivanic[24] herself admits that this approach does not easily translate into an explicit pedagogy. Instead, it is assumed that students will tacitly acquire the necessary academic literacies through participation in socially situated literacy events, where sustained participation eventually generates the production of socially purposeful texts including the production of resistant texts. At the same time, 'knowing what' or what Maton[25] (see below) refers to as the 'epistemic relations' of knowledge are back-grounded in favour of developing knower identities, termed 'social relations ${ }^{\text {, }}$.

More recently, ED practice in South Africa has picked up on arguments made by the social realist school in Bernstein's tradition of the sociology of education on the importance of 'bringing knowledge back in' and avoiding the 'blind-spot' of more constructivist approaches that tend to emphasize the learning experiences of the knower [26, 27, 28]. This school argues for the importance of recovering knowledge as a real object with its own causal powers and properties - thus resisting reducing knowledge to knowing. It views knowledge practices as emergent from but irreducible to their contexts of production. The term 'epistemological (or epistemic) access' $[29,30]$ was introduced, in contradistinction to 'social access', to capture the emphasis of according knowledge an ontologically real status independent of its knowers (to varying degrees). This approach aims to make explicit for students the specific demands of the 'grammars of inquiry', 'epistemic values' or gazes and lenses of the disciplines [31,32].

While the 'epistemic access' approach unpacks how knowledge works, the Sydney School of Systemic Functional Linguistics (SFL) $[33,34]$ unpacks how texts work - using register and genre theory to unpack disciplinary meaning-making. I argue below that these two approaches are complementary and in combination can provide a powerful theoretical and methodological framework for facilitating 'epistemic access'. By offering tools for the objectification of patterns of choices in the lexico-grammar of texts and their knowledge practices they provide a basis for developing an explicit pedagogy.

The diagram below maps these four approaches to teaching academic literacies using Maton's Legitimation Code Theory (LCT) (Specialization) [35]. An LCT analysis surfaces the principles on the basis of which knowledge practices are legitimated. Maton claims that these four gazes can be used to analyse the Humanities disciplines and sub-disciplines more generally - depending on the relative weighting of the relations represented by the two axes Subjective Relations (which valorize the identities, attributes and dispositions of knowers - what dispositions the knower should possess) and Interactional Relations (which emphasize 'ways of interacting' - how the knower should relate, usually through texts, with significant others in the field ).

1 This works well for ED practitioners who are not necessarily disciplinary experts, for it permits the foregrounding of the subjective experiences of the writer or knower and of the social relations involved in literacy practices. 


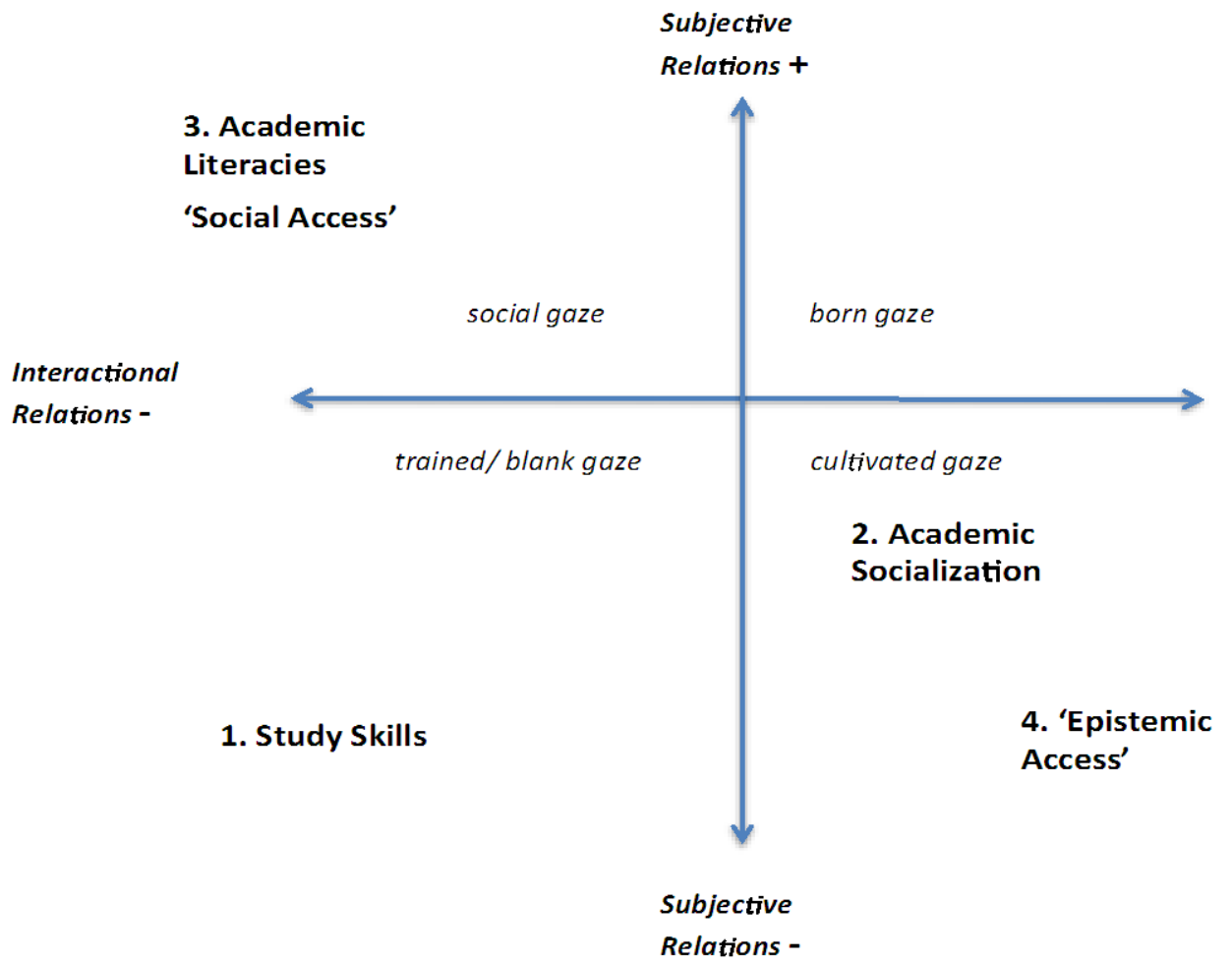

Figure 1. Mapping approaches to teaching academic literacies onto Maton's social plane for gazes LCT (Specialization) [36]

The rest of this paper is devoted to developing a theoretical framework to underpin the 'epistemic access' approach for working with Humanities disciplines and texts. As suggested by the diagram, this approach gives more emphasis to interactional relations (knowing how to interact with significant others in the field) than to subjective relations (nurturing student identities). In doing so it draws on Bernstein's[37] code theory ${ }^{2}$, elaborated by Moore[39], and his characterization of the Humanities, developed further in Maton's LCT (Specialisation). Then, in an attempt to make more explicit the ways of interacting entailed in the 'cultivated gaze' (see Figure 1), I describe Brandom's[40] analysis of inferential reasoning, which is arguably the key to mastering ways of engaging with Humanities texts. The argument is illustrated by examples from pedagogic interventions in the Extended Degrees ${ }^{3}$ in a Humanities Faculty where comprehension exercises were developed using Brandom's method to enhance students' ability to demonstrate inferential reasoning in their own writing (see Appendix A). Student scripts from these comprehension exercises were subsequently analyzed using elements of SFL.

\footnotetext{
2 Bernstein[38] defined a code as an orientation to meaning (2000).

3 The Extended Degrees are designed for 'equity students' admitted to the university on lower admissions scores because they are deemed to have suffered 'educational disadvantage'. The Extended Degrees 'stretch' the regular curriculum for a three-year Bachelor of Arts or Social Science degree over four to a maximum of six years. In addition to the regular curriculum, students are required to take introductory courses and to attend extra tutorials called 'Plus Tuts' run by ED Teaching Assistants and ED Tutors. Plus Tuts involve intensive pedagogy around assessment tasks, small group work and on-line Writing Hubs where students receive individual feedback on written work from their tutors.
}

Selected findings are presented to illustrate the extent of the challenge entailed in facilitating a capacity for inferential reasoning and therefore 'epistemic access' to the Humanities disciplines. Despite an exclusive focus on 'epistemic access', the paper concludes by recognizing that, because all knowledge claims are structured by both epistemic and social relations ${ }^{4}$ pedagogic strategies that attend to both epistemic access (unpacking and mastering the knowledge) and social access (developing the knower) are required to meet this educational challenge.

\section{The Quest for an Adequate Theory}

Bernstein wanted to make visible both the social relations and the epistemic relations entailed in the transmission of powerful knowledge. Noteworthy for ED interventions in contexts of inequality is Bernstein's claim that epistemic access to powerful knowledge or, in his terms, the distribution of opportunities for 'elaborated code' acquisition, is an indirect function of social position that may or may not be interrupted by educational opportunity [42]. Bernstein's code theory provides the theoretical starting point to our approach to giving epistemic access to the implicit 'grammar' of Humanities disciplines. His work on elaborated and restricted codes provides a clue as to how pedagogic discourses might give access to valued forms of

4 According to Maton[41] there is an epistemic relation between a knowledge claim and its object and a social relation between a knowledge claim and its subject or knower. 
knowledge. He refined his concept of code as 'a regulative principle, tacitly acquired, which selects and integrates orientations to meanings, realized as textual productions, evoked in contexts of specialized interactional practices' [43]. In a refreshing interpretation of code theory, Moore[44] (re)defines 'restricted codes' as circumscribed, shared meanings based on condensed symbols, drawing on metaphor and tied to specific contexts. Whereas 'elaborated codes' (Moore prefers 'elaborating codes') refer to the processes of explicating restricted codes by articulating their rationality, transcending their contexts and making their forms of reasoning visible. He suggests the role of pedagogic discourse is to unpack the condensed invisible meanings of restricted codes (disciplinary discourses) so that novices can learn them,

Elaborating codes have restricted codes as their objects; they make the invisible visible and provide access to their principles and mysteries. [45]

For Bernstein a code regulates both the 'what' and the 'how' of meanings through 'recognition' and 'realization rules'; these two rules are dynamically related and only analytically distinct ${ }^{5}$. 'Recognition rules' are the regulation of 'what meanings may legitimately be put together' that is, the experiential meanings and classificatory principles that enable a student to acquire a 'voice' [46]. The principles underlying 'knowing what' are regulated by the distribution of power (classification). 'Realization rules' are 'how those meanings may be legitimately made public' to create a 'message' [47]; this 'knowing how' involves the tacit acquisition of discursive resources through 'specific practices between transmitters and acquirers' in the educational 'communicative context' [48]. The principles underlying 'knowing how' are regulated by social control (framing).

In an interesting application of Bernstein's recognition and realization rules, Tapp[49] warns against focusing only on making the recognition rules explicit (here understood as the focus of the 'academic socialization' approach - see 'cultivated gaze' Figure 1. above). Instead, she advocates using the Academic Literacies approach as a complementary pedagogic strategy to allow students to practice acquiring the realization rules in safe spaces where they can carry out the necessary identity work to gain social access to the academy. Like Bernstein, she assumes the latter to be a tacit process. This paper argues similarly - that to ensure both epistemic and social access, one must work with both the recognition and realization rules and work with both the knowledge and the knowers. But a crucial difference is that, in the argument developed below, I suggest that 'knowing how' (the realization rules) can be made explicit and can therefore be brought into a powerful pedagogic discourse (elaborating code) that facilitates mastery of both rules.

Bernstein went on to distinguish between horizontal and

5 This suggests that 'knowing that' and 'knowing how' need to be kept together and not separated out into knowledge and skills or attributes as commonly practiced in study skills, outcomes-based and graduate attributes discourses. vertical discourses. Moore[50] re-interprets vertical discourses (which is what education gives access to) as esoteric, cryptic restricted codes that are relatively independent of their originating contexts. He explains that in order to abstract and then generalize; meanings must become more and more semantically dense and removed from the everyday (that is restricted). It is the function of pedagogic discourse to elaborate or unpack these condensed meanings so that students can access their reasoning.

In his late sketchy work on knowledge, Bernstein[51] rather crudely classified the Humanities as 'horizontal knowledge structures' - a series of competing 'segmented languages' that have failed to build knowledge cumulatively, due to their generally weak relation to empirical data. In keeping with his original code theory described above, he simply stated that knowing in the Humanities is 'an acquired gaze', tacitly acquired.

Maton's[52] Legitimation Code Theory (LCT) allows him to describe the knowledge structures of the Humanities disciplines more explicitly. In LCT (Specialization) Maton asks 'how is knowledge specialized?' and identifies two competing principles of legitimation that always co-exist, but can be kept analytically distinct: the 'epistemic relation' legitimates a knowledge claim with reference to the object of study and the procedures for analyzing it - foregrounding these as the basis for claims to truth, and the 'social relation' legitimates a knowledge claim by reference to the characteristics, dispositions and voice of knower foregrounding these as the basis for authority and power within a field. These principles allow Maton to identify different 'specialisation codes'. He identifies the Humanities as 'knower codes' where it is the specialized dispositions and attributes of the knowers that are emphasized. ${ }^{6}$ At a more delicate level of analysis, he describes a range of 'gazes' and 'lenses' within 'knower codes' by distinguishing between two kinds of social relations: subjective relations (SubR), where the 'kind of knower' is emphasized, compared with interactional relations (IR), where 'ways of knowing' are emphasized (see Figure 1 above). Maton privileges the 'cultivated gaze' that strongly controls how to relate to the works of significant others.

Following Bernstein, he notes that this often involves acquiring a 'feel' for practices through sustained exposure to exemplary models or prolonged apprenticeship. His analysis allows us to assume that in higher education in the Humanities we are mostly working with 'knower codes' and 'cultivated gazes'. It is particularly Maton's 'interactional relations with significant others', the hallmark of the 'cultivated gaze', that is important for the argument developed here; for it explicates Bernstein's realization rules

6 The Social Sciences sit somewhere in between - but are predominantly also knower codes, (see Luckett \& Hunma[53] for an identification of differences between Humanities and Social Science disciplines using Maton's categories).

7 Maton[54] argues that one effect of the linguistic turn (1960s -1970s) has been to further complicate the Humanities and Social Sciences fields; new knower codes have been introduced that relativize and break with past epistemologies, carrying new gazes and even more specialised dispositions ('lenses'). 
and his emphasis on the tacit acquisition of specialized discursive resources for knowing how to create a legitimate text.

But the pedagogic challenge remains: how far is it possible to elaborate and make explicit the 'interactional practices' of the gazes in the Humanities so that students produce legitimate texts through which they display the 'right kind of knower' discourses, attributes and dispositions? For this Robert Brandom's[55] work on inferential reasoning was recruited. ${ }^{8}$ Brandom's idea that making a knowledge claim entails knowing 'how to give and ask for reasons' was used to develop explicit pedagogic discourses in the form of reading comprehension materials that we hoped would enable students to realize the specialized but implicit ways of working with academic texts in the Humanities. Indeed, Brandom argues that it is possible to make explicit the implicit 'interactional practices' for making knowledge claims, rational commitments and beliefs. Advocating a pragmatic and expressive theory of language, ${ }^{9}$ he argues for the privileging of inference over reference and representation. ${ }^{10} \mathrm{He}$ makes the extraordinary claim that the linguistic and social practices of 'giving and asking for reasons' have a privileged place in a theory of knowledge, that this is what makes thinking possible [57]. ${ }^{11} \mathrm{He}$ asks what is distinctive about the conceptual and suggests that really grasping propositional knowledge involves knowing how to do something with it - knowing how to apply a concept to it and how to articulate the inferential reasoning and consequences entailed in using a concept. Knowers need to know how to test the 'assertibility conditions' for knowledge claims. This requires sorting out the reasons and commitments entailed in taking a claim as true, grasping the conditions necessary for the truth of a claim and the practical reasoning involved in acting as if it were true. This implies a form of 'practical mastery' that can be made explicit [58]. Furthermore, this requires not only understanding propositional and conceptual content, but also the web of relations to other concepts and associated inferences entailed in working with them - 'a concept is meaningful only through its inferential relations to other concepts' [59].

\footnotetext{
8 Given our commitment to embedding ED work in the disciplines, Brandom's generic criteria for inferential reasoning were adapted to disciplinary contexts by the TAs - the literature on argument and critical thinking suggests that there is a role for both generic and embedded approaches [56]. In addition, Brandom's emphasis on the importance of applying concepts to phenomena led us to introduce the idea of getting students to define key concepts in their home languages by developing multi-lingual glossaries of terms in small groups. Students appear to enjoy this exercise, but we are yet to evaluate its impact and so it is not reported on here.

9 Brandom's approach is compatible with Halliday's functional linguistics in so far as the starting point for his analysis is language-in-use.

10 In SFL terms this would mean privileging logical over experiential meanings.

11 Brandom's position is aligned with that of the social realist school insofar as he argues that the discursive norms around how to make legitimate inferences and judgments when using concepts have developed over time through social interaction; these are cultural but not arbitrary emergent from the properties of the objects that they are about, as well as the history of the concept-in-use. He points to a certain social objectivity in the practices of making and taking up knowledge claims that goes beyond the subjectivities of the knowers.
}

\section{Application and Further Analysis Using SFL}

The application of Brandom's ideas to pedagogic practice reported on here was not set up as a formal research project, but rather as an action research project embedded in ED work with disadvantaged students in a Humanities Faculty. The intervention involved ED academics and a team of Teaching Assistants (TAs) and Tutors who design and run supplementary tutorials in first and second year courses in eight departments. A set of 'Brandom-type Questions', based on Brandom's theory of making inferential reasoning explicit, were developed, circulated and discussed at a training workshop on designing materials for assisting students to unpack prescribed readings (see Appendix A). TAs re-worked the questions for specific disciplinary texts for students to work on in their tutorials (see examples in Appendices B \& C). At a follow-up workshop and in some of the formal evaluation comments, TAs and tutors reported that these exercises did successfully force students to undertake a close reading of the texts. However, they also reported that when marks were allocated, the Brandom-type Questions produced a much wider distribution of marks than previously - including higher failure rates. Additionally, evaluation feedback suggested that some of the tutors were unable to provide sufficiently diagnostic feedback to enable students to improve ${ }^{12}$. This suggests that while the Brandom-type exercises appear to have assisted students to unpack meanings in their readings - that is, to begin to acquire the recognition rules for reading - we were still failing to help weaker students to acquire the realization rules for creating legitimate academic texts.

In order to diagnose why some students were failing to realize adequate written responses to the Brandom-type exercises, I turned to the 'embedded literacy' work of the Sydney School of SFL [60-64]. In a recent paper on 'embedded literacy', Martin[65] claims that when students enter university it is assumed that they have mastered a shift in the relationship between wordings and meanings from congruent, everyday grammar to grammatically metaphorical non-congruent ways of making meaning. He notes 'ideational metaphor is a critical resource' for writing technical abstract texts and high stakes academic writing and those students will not succeed in assessment without it [66].

So what exactly is 'ideational metaphor'? Simply put, it involves realizing the semiotic, institutionalized practices of the academy through using non-congruent metaphorical grammatical devices to achieve high levels of abstraction and semantic density. This entails a shift from realizing personal actors and dialogically direct meanings occurring in concrete contexts to public, objective and synoptic meanings that are dialogically indirect, occurring in institutionalized textual spaces. In other words the challenge is to explicitly teach the grammar that enables students to realize in writing

12 See Humanities Education Development Unit's 'Writing Hub Evaluation', June 2015 . 
what Bernstein described as elaborated code (see above).

Data for the SFL analysis was obtained from marked students' scripts selected from first class and fail categories in a first-year history course and an introductory social studies course. I report here on the analysis of only four scripts, two with top-range scores and two that failed. The analysis and findings are presented for illustrative purposes, they are too superficial and tentative to hold any empirical significance; but rather point to a need for further implementation and evaluation research.

The historical studies scripts analyzed were students' answers to question 3 of the Brandom-type comprehension set as an assessed tutorial exercise (see Appendix B). The social studies scripts analyzed were answers to question 3 of a comprehension exercise which students were later required to rework into an essay (see Appendix C). In each case the two scripts compared had roughly the same number of clauses.

The method of analysis was a selective use of SFL - that is, only those elements that would reveal students' choices of experiential and logical meanings were used (what is going on in the text, how the world is represented and what relationships are set up between the representations). Thus, in terms of register I looked only at Field and in terms of discourse semantics only at ideation and conjunction. For each text the clauses were first identified and the types of processes (verbs) for each clause. This was followed by a more detailed analysis using Martin's (2013) concepts discussed below - power words (experiential metaphor), power grammar (logical metaphor), flexi-tech terms and specialized terms. These categories seemed to work well for both sets of texts (see Appendix D).

Martin uses the terms 'power words' and 'power grammar' to teach 'ideational metaphor' to teachers ${ }^{13}$. 'Power words' are 'experiential metaphors' where a figure (a whole clause in which entities, activities and settings are realized grammatically as participants, processes and circumstances respectively) gets condensed into a single participant or circumstance (usually through nominalization or the construction of nominal groups as participants and by prepositional phrases and adverbs as circumstances). The use of experiential metaphor often entails a shift in process types (verbs) from concrete, material activities to causative or identifying processes or states; often simply the verb to be or to have [67]. For example, in History Script A the student might have written in congruent form 'In this chapter the author argues that' followed by a second dependent clause (Circumstance ${ }^{\wedge}$ Participant ${ }^{\wedge}$ Process [dependent clause]) but instead condenses this figure into a single nominal group where the argument becomes an abstract thing, 'The overall argument of this chapter' which now functions as the Participant of an Identifying Relational Process 'is' in a single clause. The Relational Process 'is' is further defined by an embedded clause that carries a second Relational

13 For the purposes of this project we did not include Martin's third concept, 'power composition'.
Process condensed into a Circumstance of cause 'due to' that can then be followed by a second abstract nominal group 'economic and political factors'.

\||The overall argument of this chapter is [[that Islamic expansion during this time period was largely due to economic and political factors.]] |||

However, in History Script B, one can see that the student uses predominantly congruent grammatical forms,

|| In this chapter one can see $\|$ that Risso is forming the argument about [[how Islamism was spread]] and [[how it came to be such a powerful religion.]] II

The use of experiential and logical metaphor enables student A to give the author's reasons for the expansion of Islam, all within one clause. This kind of writing is typical of the abstracted, condensed meanings used in academic discourses. In contrast the extract below from History Script B shows that this student largely fails to realize the required level of abstraction, his writing resembles a spoken, more context-dependent register. For example - he includes the author (she) and 'other academics' as a concrete participants and he uses conjunctions between clauses to set up logical relations (because, and),

|| This is $\|$ because $<<$ what she is writing $>>$ she wants $\|$ to be taken seriously

|| and she wants $\|$ to make her argument one [[which other academics will take notice of.]] |||

As illustrated in the example from Script A above, 'power grammar' or 'logical metaphor' is realized when implication sequences of actions are re-coded so that the conjunctive relations between the actions (conjunctions between independent clauses, such as 'because') are realized within the clause as a circumstance ('due to') or a preposition or dependent clause. This permits a higher level of abstraction from the original context of the action and permits new logical relations to be set up between abstract or condensed participants within the clause ('Islamic expansion', 'economic and political factors'). This may entail greater usage of dependent clauses in clause complexes to indicate nuanced processes of reasoning, causality, conditions, concessions and so on - all required for demonstrating the careful processes of inferential reasoning. This high level of grammatical intricacy usually involves projection (use of verbal and mental processes to project embedded clauses) and expansion (use of enhancing and elaborating relations with fewer extending relations)[68]. In the Humanities these grammatical devices enable a complex flow of unpacking and repackaging meanings as inferential reasoning moves between theory or interpretation and data, evidence or references to other texts.

In addition, under the concept 'power words', Martin[69] includes 'specialized terms' specific to a particular register and discourse, and 'flexi-tech terms', which are loosely classified technical terms typically used in the Human and 
Social Sciences. In the History Script A an example of a flexi-tech term would be 'economic and political factors' and specialized terms would be 'the Umayyad dynasty and caliphs' (see Appendix D for further examples).

\section{Findings}

The limited results of the SFL analyses are presented in detail in Appendix D and summarized in the tables below. In each case Script A is a high-scoring script and Script B a low-scoring script.

Table 1. Summary of Patterns of Ideational Meanings in the History Scripts

\begin{tabular}{|c|c|c|c|c|}
\hline & $\begin{array}{c}\text { Experiential } \\
\text { Metaphor }\end{array}$ & $\begin{array}{c}\text { Logical } \\
\text { Metaphor }\end{array}$ & $\begin{array}{c}\text { Flexi-tech } \\
\text { Terms }\end{array}$ & $\begin{array}{c}\text { Specialized } \\
\text { Terms }\end{array}$ \\
\hline Script A & 11 & 6 & 6 & 1 \\
\hline Script B & 4 & 0 & 0 & 1 \\
\hline
\end{tabular}

Table 2. Summary of Patterns of Ideational Meanings in the Social Studies Scripts

\begin{tabular}{|c|c|c|c|c|}
\hline & $\begin{array}{c}\text { Experiential } \\
\text { Metaphor }\end{array}$ & $\begin{array}{c}\text { Logical } \\
\text { Metaphor }\end{array}$ & $\begin{array}{c}\text { Flexi-tech } \\
\text { Terms }\end{array}$ & $\begin{array}{c}\text { Specialized } \\
\text { Terms }\end{array}$ \\
\hline Script A & 10 & 5 & 3 & 2 \\
\hline Script B & 13 & 0 & 1 & 3 \\
\hline
\end{tabular}

These tentative findings suggest that the discrepancies between the strong and weak scripts may lie in their use of ideational metaphor. It is interesting to note that in the case of 'power grammar' (logical metaphor) some of the weak scripts demonstrated no usage of this device at all. This may indicate that some students have not yet mastered the grammatical resources for condensing meanings within the clause and for setting up chains of inferential reasoning within clauses. If this diagnosis is correct, this is likely to be a major constraint in their ability to realize the moves entailed inferential reasoning, that is, to set up logical relationships between abstract concepts and things.

This limited analysis of only four scripts suggests that some South African students from disadvantaged schools, who speak English as an additional language, arrive at university without having mastered the realization rules for construing legitimate texts in elaborating codes. This severely constrains their ability to demonstrate in writing the interactional relations and ways of giving and asking for reasons identified by Maton and Brandom as so highly valued in the Humanities disciplines. Instead their writing often reads as long-winded, overly concrete and weak in argument or analysis - in other words - as failing to demonstrate the chains of inferential reasoning that the elaborating codes that academic discourses demand.

\section{Conclusions}

This paper has given a glimpse of what the specialized interactional practices and grammars of the Humanities knower codes entail. As argued above, it is the interactional practices that entail inferential reasoning using experiential and logical metaphor that are most prized in the "cultivated gazes'. But, I argue, the teaching of this is invariably overlooked or left implicit in pedagogic practice in universities. The analysis of student scripts using SFL suggests that, although the Brandom-type comprehension exercises may have made explicit for students the recognition rules required for reading and unpacking academic texts, they failed to make explicit the realization rules for writing legitimate academic texts. The work of the Sydney School suggests that this involves explicitly teaching the grammatical forms (the use of ideational metaphor in particular) that realize the semiotic practices of the academy. Thus the next phase of the work-in-progress reported here we will train TAs and tutors to use Martin's concepts 'power words' and 'power grammar' in their work on disciplinary texts with students. The impact of this work will be the subject of another paper.

\section{Postscript}

This paper has focused on the challenge of facilitating 'epistemic access' to the Humanities disciplines. However, if we accept Maton's[70] classification of the Humanities as 'knower codes' where subjective relations (as well as interactional relations) are implicated in knowledge practices, the argument of this paper should not be understood to imply discounting the contribution of the academic literacies approach - with its focus on developing knower identities, voices and dispositions. Instead, if higher education is to interrupt the reproduction of social structure, both approaches, 'epistemic access' (emphasizing the interactional relations involved in the mastery of texts) and 'social access' (emphasizing subjective relations), are understood as necessary and complementary - with neither being sufficient on its own. Moore makes this observation in the UK context,

The demand for the message system (of the school) is to 'speak in elaborated' but for many pupils that message is heard through a voice that is not only alien to their own but which also appears to devalue and denigrate their own voice. They do not hear 'speak in elaborated' but 'speak in posh', or 'speak in white'. For such pupils, voice swamps and silences message.[71]

His concern is even more acute in Southern post-colonial contexts.

\section{Acknowledgments}

This work is based on the research supported wholly by the National Research Foundation of South Africa (Grant Number CPRR13091339042 No: 91543). 


\section{Appendix A: Brandom-Type Questions}

1. What is this text about?

2. What is the context in which it was written?

3 . What position is the author taking up?

4. What/ who is $\mathrm{s} /$ he arguing against?

5. What are the key concepts is $\mathrm{s} / \mathrm{he}$ is using in this text?

6. What is $\mathrm{s} / \mathrm{he}$ making a claim about? How strongly? (note adverbs, adjectives)

7. Is s/he entitled to make this claim?

8. What evidence does $\mathrm{s} / \mathrm{he}$ use to back her claim?

9. If you accept her claim as true, what else are you committing yourself to?

10. Does this claim match what you already know about this issue /topic?

11. What other positions/ claims that you know about support / challenge this claim?

12. Can you spot any key grammatical devices that students should be alerted to in order to follow the author's argument / inferential reasoning?

\section{Appendix B: Historical Studies}

Tutorial 3. Reading an Academic Text: Merchants and Faith

1. What information can you obtain from the cover of the book and its title page? What does this suggest about the reliability and usefulness of the text?

2. Note the differences between argument and evidence in the text. Give a specific example from the text of an argument and then of evidence that Risso uses to substantiate the argument (don't forget to cite the page number of your examples).

3. What do you think is the overall argument of this chapter? How does it relate to the theme of the book? How has it influenced the evidence that Risso provides in this chapter?

4. Risso makes reference in her text to other historians and their interpretations. Why do you think she does this? How does it contribute to her arguments?
5. Look carefully at the footnotes. What different functions do they serve? Give a specific example of each. Why do you think footnotes are an important part of academic writing?

\section{Appendix C: Social Studies}

Biko's use of the concept "race" in "I Write What I Like", Chapter 6 'We Blacks' $[72]^{14}$

1. What was the original purpose of this text?

2. What are the main concepts Biko uses in this text to represent 'race'?

3. Exactly how does Biko define the concept black (ness) and what does this tell us about how he uses the concept 'race'? (also see Biko, 1978:52 Chapter 6, in the course reader, for further definitions).

4. What is the main claim that Biko makes about the effects of racialized oppression on black people in South Africa?

5. Is he entitled to make this claim? What evidence does he use to back his claim?

6. If you were a black person living in South Africa in the 1970s and 1980s and you accepted Biko's claims as true, what would you be committing yourself to?

7. Can you guess from his use of language, what Biko's position might have been with regard to gender relations? Back up your answer with quotes from the text.

8. What other positions do you know about that would challenge the Black Consciousness position?

9. For group discussion: To what extent do you think Black Consciousness is still relevant to South African society today? Give reasons for your answer.

\section{Essay Question Based on Question No. 3:}

"Being black is not a matter of pigmentation - being black is a reflection of mental attitude." (Biko, 1978:52). Describe what Biko meant by this statement, and write an essay in which you critically evaluate Biko's understanding of 'race'.

14 The selection of a political text with canonical status (rather than an academic text) was deliberate for two reasons: a) the text is very accessible b) most black students find it very difficult to get a critical distance from Biko's position and assumptions. 


\section{Appendix D: Data Analysis}

1) Comparison of Experiential and Logical Metaphor in the History Scripts

\begin{tabular}{|c|c|c|c|}
\hline \multirow[t]{2}{*}{ Totals } & \multicolumn{3}{|c|}{ History Script A } \\
\hline & $\begin{array}{l}\text { Clause } \\
\text { No. }\end{array}$ & Experiential Metaphor & Transitivity Element \\
\hline & 1. & The overall argument of this chapter & Carrier in Pr: relational \\
\hline & 1. & Islamic expansion & Carrier in Pr: relational \\
\hline & 3. & Islam and its consequential spread & Goal \\
\hline & 4. & spreading Islam & Phenomenon \\
\hline & 5. & to their "control over significant maritime trade" & Circ: cause: reason \\
\hline & 8. & economic factors and Islamic trading & Token in Pr: relational \\
\hline & 8. & to the expansion of Islam & Circ: Value in Pr: relational \\
\hline & 9. & the information and evidence & Phenomenon in Pr: mental \\
\hline & 9. & $\begin{array}{l}\text { with a focus on the geographical expansion and trading } \\
\text { routs of Islamic expansion }\end{array}$ & Circ: cause: purpose \\
\hline & 9. & in the provision of a map & Circ: manner: means in Pr: mental \\
\hline & 10. & the expansion of Islam around and through trading cities & Phenomenon in Pr: mental \\
\hline \multicolumn{4}{|l|}{11} \\
\hline & & Logical Metaphor & Transitivity Element \\
\hline & 1. & was largely due to (cause in the clause) & Circ: cause: reason in Pr: relational \\
\hline & 3. & $\begin{array}{l}\text { [that influenced the trade] [that helped to strengthen } \\
\text { Islam] (implication sequence within the clause) }\end{array}$ & embedded clauses in Pr: material \\
\hline & 4. & $\begin{array}{c}\text { as a way [to gain control over commodities, trade routes } \\
\text { and customs revenues] }\end{array}$ & Prepositional phrase \\
\hline & 5. & due to their control over ... & Circ: cause: reason in Pr: relational \\
\hline & 8. & led (cause in the clause) & Pr: relational \\
\hline & 9. & this has influenced (cause in the clause) & Pr: mental \\
\hline \multicolumn{4}{|l|}{6} \\
\hline & & Flexi-tech Terms & Transitivity Element \\
\hline & 1. & economic and political factors & Attribute in Pr: relational \\
\hline & 2. & trade and military force & Value in Pr: relational \\
\hline & 3. & political and economic factors & Phenomenon in Pr: mental \\
\hline & 4. & commodities, trade routes & Phenomenon in Pr: mental \\
\hline & 5. & Islamic power & Carrier in Pr: relational \\
\hline & 8. & economic factors & Carrier in Pr: relational \\
\hline \multicolumn{4}{|l|}{6} \\
\hline & & Specialised Terms & Transitivity Element \\
\hline & 4. & the Umayyad dynasty and caliphs & Senser in Pr: mental \\
\hline 1 & & & \\
\hline
\end{tabular}




\begin{tabular}{|c|c|c|c|}
\hline \multirow[t]{2}{*}{ Totals } & \multicolumn{3}{|c|}{ History Script B } \\
\hline & $\begin{array}{l}\text { Clause } \\
\text { No. } \\
\end{array}$ & Experiential Metaphor & Transitivity Element \\
\hline & 9. & the reader of her text & Phenomenon in Pr: mental \\
\hline & 9. & to an understanding & Circ: cause: purpose \\
\hline & 9. & of what she's writing about & Circ: matter \\
\hline & 10. & on her side of the argument & Circ: accompaniment: comitative \\
\hline \multicolumn{4}{|l|}{4} \\
\hline & & Logical Metaphor & Transitivity Element \\
\hline \multicolumn{4}{|l|}{$\mathbf{0}$} \\
\hline & & Flexi-tech Terms & Transitivity Element \\
\hline \multicolumn{4}{|l|}{$\mathbf{0}$} \\
\hline & & Specialised Terms & Transitivity Element \\
\hline & $\begin{array}{c}2,3,7 \\
8\end{array}$ & sources, academic sources & Goal in Pr: material or Phenomenon in Pr: mental? \\
\hline 1 & & & \\
\hline
\end{tabular}

\section{2) Comparison of Experiential and Logical Metaphor in the Social Studies Scripts}

\begin{tabular}{|c|c|c|c|}
\hline \multirow[t]{2}{*}{ Totals } & \multicolumn{3}{|c|}{ Social Studies Script A } \\
\hline & $\begin{array}{l}\text { Clause } \\
\text { No. }\end{array}$ & Experiential Metaphor & Transitivity Element \\
\hline & 2. & by implication & Circ: manner: means \\
\hline & 3. & racial discrimination & Goal in P: material \\
\hline & 3. & in apartheid South Africa & Circ: location spatial \\
\hline & 3. & under the umbrella of blackness & Circ: role \\
\hline & 4. & in the struggle towards their liberation & Circ: contingency condition \\
\hline & 5. & In his definition of blackness & Circ: matter \\
\hline & 5. & (a)way from the essentialist viewpoint of race & Phenomenon in Pr: mental \\
\hline & 5. & as an oppressed black man in apartheid South Africa & Circ: role \\
\hline & 6. & the concept of blackness & Value in Pr: relational \\
\hline & 8. & the apartheid South Africa('s) racial language & Phenomenon in Pr: mental \\
\hline \multicolumn{4}{|l|}{10} \\
\hline & & Logical Metaphor & Transitivity Element \\
\hline & 2. & By doing this & Prep. phrase \\
\hline & 2. & as a factor [in determining race] & Prep. phrase \\
\hline & 6. & a way of thinking about race & Phenomenon in Pr: mental / Prep phrase \\
\hline & 6. & to (not only) take ownership of & Pr: relational possessive \\
\hline & 7. & in Biko's evaluation of whiteness & Circ: matter /Nominal group \\
\hline \multicolumn{4}{|l|}{5} \\
\hline & & Flexi-tech Terms & Transitivity Element \\
\hline & 1. & politically, economically and socially & Circ: manner \\
\hline & 1. & in apartheid South Africa & Circ: location: spatial \\
\hline & 6. & a social construct & Value: Pr: relational \\
\hline \multicolumn{4}{|l|}{3} \\
\hline & & Specialised Terms & Transitivity Element \\
\hline & 2. & blackness & Phenomenon in Pr: mental \\
\hline & 8. & whiteness & Verbiage in Pr: verbal \\
\hline 2 & & & \\
\hline
\end{tabular}




\begin{tabular}{|c|c|c|c|}
\hline \multirow[t]{2}{*}{ Totals } & \multicolumn{3}{|c|}{ Social Studies Script B } \\
\hline & $\begin{array}{l}\text { Clause } \\
\text { No. }\end{array}$ & Experiential Metaphor & Transitivity Element \\
\hline & 1. & in his definition of black consciousness & Circ: matter \\
\hline & 1. & [being black] & Phenomenon in Pr: mental \\
\hline & 1. & as (not) a matter of pigment & Circ: matter \\
\hline & 1. & as a reflection of a mental attitude & Circ: matter \\
\hline & 1. & a subservient being & Value in Pr: identifying \\
\hline & 3,4 & the aspiration of whiteness & Value/ Possession in Pr: relational \\
\hline & 5. & by the oppressors rule & Circ: contingency condition \\
\hline & 10. & the process of racialization & Goal in Pr: material \\
\hline & 11 & biological conceptions of race & Phenomenon in Pr: mental \\
\hline & 11. & the British imperial strategy & Actor in Pr: material \\
\hline & 11. & the need for bureaucratic parsimony & Actor in Pr: material \\
\hline & 11. & in a docile state of colonial law and order & Circ: contingency condition \\
\hline \multicolumn{4}{|l|}{13} \\
\hline & & Logical Metaphor & Transitivity Element \\
\hline \multicolumn{4}{|l|}{$\mathbf{0}$} \\
\hline & & Flexi-tech Terms & Transitivity Element \\
\hline & 7. & idiology & Value in Pr: identifying \\
\hline \multicolumn{4}{|l|}{1} \\
\hline & & Specialised Terms & Transitivity Element \\
\hline & 1,6 & blackness & Goal in Pr: material \\
\hline & 3 & non-white & Value in Pr: identifying \\
\hline & 6 & whiteness & Value in Pr: identifying \\
\hline 3 & & & \\
\hline
\end{tabular}

[6] Ivanic, R. Discourses of writing and learning to write. Language and Education. 18: 3: 220-245. 2004.

\section{REFERENCES}

[1] Council on Higher Education. A proposal for undergraduate curriculum reform in South Africa: A case for a flexible curriculum structure. Pretoria: CHE. 2013.

[2] Boughey, C. Academic Development for improved efficiency in the higher education and training system in South Africa. Pretoria: Development Bank of South Africa. 2010.

[3] Tapp, J. Framing the curriculum for participation: a Bernsteinian perspective on academic literacies, Teaching in Higher Education, 20:7, 711-722, doi: 10.1080/13562517.2015.1069266. 2015.

[4] Boughey, C. Academic Development for improved efficiency in the higher education and training system in South Africa. Pretoria: Development Bank of South Africa. 2010.

[5] Gee, P. Social Linguistics and Literacies: Ideology in Discourse. London: Falmer Press. 1996.
[7] Lea, M.R. \& Street, B.V. Student writing in higher education: an academic literacies approach. Studies in Higher Education. 23:2: 157-172. 1998.

[8] Street, B. Social Literacies: Critical approaches to literacy in education, development and ethnography. London: Longman. 1995.

[9] Tapp, J. Framing the curriculum for participation: a Bernsteinian perspective on academic literacies, Teaching in Higher Education, 20:7, 711-722, doi: 10.1080/13562517.2015.1069266. 2015.

[10] Lea, M.R. \& Street, B.V. Student writing in higher education: an academic literacies approach. Studies in Higher Education. 23:2: 157-172. 1998.

[11] Muller, J. Every picture tells a story: Epistemological access and knowledge (keynote address presented to the Knowledge \& Curriculum Symposium, University of Cape Town, 7-8 November, 2012. 
[12] Maton, K. Knowledge and Knowers: Towards a realist sociology of education. London: Routledge. 2014.

[13] Ivanic, R. Discourses of writing and learning to write. Language and Education. 18: 3: 220-245. 2004.

[14] Boughey, C. Academic Development for improved efficiency in the higher education and training system in South Africa. Pretoria: Development Bank of South Africa. 2010.

[15] Boughey, C. Academic Development for improved efficiency in the higher education and training system in South Africa. Pretoria: Development Bank of South Africa. 2010.

[16] Hasan, R. \& Williams, G. (Eds.) Literacy in society. London. Addison Wesley Longman. 1996.

[17] Hyland, K. Genre and second language writing. Ann Arbor: University of Michigan Press. 2004.

[18] Swales, J. Genre analysis: English in academic and research settings. Cambridge, UK: Cambridge University Press. 1990.

[19] Ivanic, R. Discourses of writing and learning to write. Language and Education. 18: 3: 220-245. 2004.

[20] Rose, D., \& Martin, J. R. Learning to write, Reading to learn: Genre, knowledge and pedagogy in the Sydney School. London: Equinox. 2012.

[21] Lea, M.R. \& Street, B.V. Student writing in higher education: an academic literacies approach. Studies in Higher Education. 23:2: 157-172. 1998

[22] Coffin, C. \& Donohue, J.P. Academic Literacies and systemic functional linguistics: How do they relate? Journal of English for Academic Purposes.11: 64-75. 2012.

[23] Tapp, J. Framing the curriculum for participation: a Bernsteinian perspective on academic literacies, Teaching in Higher Education, 20:7, 711-722, doi: 10.1080/13562517.20 15.1069266. 2015.

[24] Ivanic, R. Discourses of writing and learning to write. Language and Education. 18: 3: 220-245. 2004, p. 235.

[25] Maton, K. Knowledge and Knowers: Towards a realist sociology of education. London: Routledge. 2014.

[26] Maton, K., \& Moore, R. (Eds.) Social Realism, Knowledge and the Sociology of Education: Coalitions of the mind. London: Continuum. 2010.

[27] Moore, R. Basil Bernstein: The thinker and the field. Oxon: Routledge. 2013.

[28] Young, M.F.D. Bringing Knowledge Back In: From social constructivism to social realism in the sociology of education. Abingdon: Routledge. 2008.

[29] Morrow, W. Bounds of Democracy: Epistemological Access in Higher Education. Cape Town, South Africa: Human Sciences Research Council. 2009.

[30] Muller, J. Every picture tells a story: Epistemological access and knowledge (keynote address presented to the Knowledge \& Curriculum Symposium, University of Cape Town, 7-8 November 2012.

[31] Maton, K. Knowledge and Knowers: Towards a realist sociology of education. London: Routledge. 2014.
[32] Luckett, K. \& Hunma, A. Making gazes explicit: facilitating epistemic access in the Humanities. Higher Education. 67: 183-198. 2014.

[33] Halliday, M.A.K. An Introduction to Functional Grammar. $2^{\text {nd }}$ Edition. London: Edward Arnold. 1994.

[34] Martin, J. \& Rose, D. Working with discourse: Meaning beyond the clause. London: Equinox. 2003.

[35] Maton, K. Knowledge and Knowers: Towards a realist sociology of education. London: Routledge. 2014.

[36] Maton, K. Knowledge and Knowers: Towards a realist sociology of education. London: Routledge. 2014, p.186.

[37] Bernstein, B. Class, Codes and Control: the structuring of pedagogic discourse.Vol.4. New edition. London: Routledge. 2003.

[38] Bernstein, B. Class, Codes and Control: the structuring of pedagogic discourse.Vol.4. New edition. London: Routledge. 2003.

[39] Moore, R. Basil Bernstein: The thinker and the field. Oxon: Routledge. 2013.

[40] Brandom, R. Articulating Reasons: An introduction to interferentialism. Cambridge, Mass.: Harvard University Press. 2000.

[41] Maton, K. Knowledge and Knowers: Towards a realist sociology of education. London: Routledge. 2014.

[42] Bernstein, B. Class, Codes and Control: the structuring of pedagogic discourse.Vol.4. New edition. London: Routledge. 2003.

[43] Bernstein, B. Class, Codes and Control: the structuring of pedagogic discourse.Vol.4. New edition. London: Routledge. 2003, p.15.

[44] Moore, R. Basil Bernstein: The thinker and the field. Oxon: Routledge. 2013.

[45] Moore, R. Basil Bernstein: The thinker and the field. Oxon: Routledge. 2013. p.64..

[46] Bernstein, B. Class, Codes and Control: the structuring of pedagogic discourse.Vol.4. New edition. London: Routledge. 2003, p. 29-32.

[47] Bernstein, B. Class, Codes and Control: the structuring of pedagogic discourse.Vol.4. New edition. London: Routledge. 2003, p. 32.

[48] Bernstein, B. Class, Codes and Control: the structuring of pedagogic discourse.Vol.4. New edition. London: Routledge. 2003, p. 34.

[49] Tapp, J. Framing the curriculum for participation: a Bernsteinian perspective on academic literacies, Teaching in Higher Education, 20:7, 711-722, doi: 10.1080/13562517.2015.1069266. 2015.

[50] Moore, R. Basil Bernstein: The thinker and the field. Oxon: Routledge. 2013.

[51] Bernstein, B. Pedagogy, Symbolic Control and Identity: theory, research, critique. $2^{\text {nd }}$ edition. Lanham, Maryland: Rowman \& Littlefield. 2000. 
[52] Maton, K. Knowledge and Knowers: Towards a realist sociology of education. London: Routledge. 2014.

[53] Luckett, K. \& Hunma, A. Making gazes explicit: facilitating epistemic access in the Humanities. Higher Education. 67: 183-198. 2014.

[54] Maton, K. Knowledge and Knowers: Towards a realist sociology of education. London: Routledge. 2014.

[55] Brandom, R. Articulating Reasons: An introduction to interferentialism. Cambridge, Mass.: Harvard University Press. 2000

[56] Coffin, C. \& O' Halloran, K. Researching argumentation in educational contexts: new directions, new methods. International Journal of Research \& Method in Education, 31(3), 219-227. 2008. doi:10.1080/1737270802416582.

[57] Brandom, R. Articulating Reasons: An introduction to interferentialism. Cambridge, Mass.: Harvard University Press. 2000, p. 27.

[58] Brandom, R. Articulating Reasons: An introduction to interferentialism. Cambridge, Mass.: Harvard University Press. 2000, p. 6.

[59] Brandom, R. Articulating Reasons: An introduction to interferentialism. Cambridge, Mass.: Harvard University Press. 2000, p. 15.

[60] Halliday, M.A.K. An Introduction to Functional Grammar. $2^{\text {nd }}$ Edition. London: Edward Arnold. 1994.

[61] Martin, J. \& Rose, D. Working with discourse: Meaning beyond the clause. London: Equinox. 2003.
[62] Martin, J. \& Rose, D. Genre Relations: Mapping Culture. London: Equinox. 2008.

[63] Rose, D., \& Martin, J. R. Learning to write, Reading to learn: Genre, knowledge and pedagogy in the Sydney School. London: Equinox. 2012.

[64] Macnaught L., Maton K., Martin J.R. \& Matruglio E. Jointly constructing semantic waves: Implications for teacher training. Linguistics and Education. 24: 50-63. 2013.

[65] Martin, J. Embedded literacy: Knowledge as meaning Linguistics and Education.24: 23-37. 2013

[66] Martin, J. Embedded literacy: Knowledge as meaning Linguistics and Education.24: 23- 37. 2013, p.28.

[67] Christie, P. \& Derewianka, B. School Discourse: Learning to Write across the Years of Schooling. London: Continuum. 2008.

[68] Christie, P. \& Derewianka, B. School Discourse: Learning to Write across the Years of Schooling. London: Continuum. 2008.

[69] Martin, J. Embedded literacy: Knowledge as meaning Linguistics and Education.24: 23- 37. 2013.

[70] Maton, K. Knowledge and Knowers: Towards a realist sociology of education. London: Routledge. 2014.

[71] Moore, R. Basil Bernstein: The thinker and the field. Oxon: Routledge. 2013, p. 88.

[72] Biko, S. I Write What I Like. Johannesburg: Picador Africa. 1978, pp.29-35. 